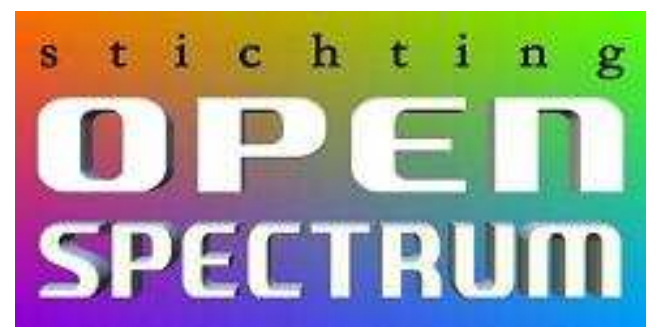

\title{
Spectrum reform: too much is not enough
}

\author{
by \\ Robert Horvitz \\ Open Spectrum Foundation \\ Amsterdam / Prague \\ http://www.openspectrum.info/
}

\begin{abstract}
Based on a presentation at a workshop on "Spectrum Reform in the UK: Has all the thinking now been done?” organised at the London School of Economics by the Warwick School of Business' Centre for Management under Regulation on 6 July 2007. This version incorporates information from the Powerpoint slides, highlights the "more thought needed" suggestions, streamlines the main argument and fixes typographic and factual errors in the handout.
\end{abstract}

The programme says I am to talk about the "need for more unlicenced spectrum." In fact I won't have much to say about that, since the Licence Exempt Framework Review ${ }^{1}$ (LEFR) proposes to expand the allocation of licence exempt spectrum from 18 to $342 \mathrm{GHz}$, which is unexpectedly generous. Aside from the fact that most of this spectrum is above $105 \mathrm{GHz}$ and equipment operating in that range is not yet commercially available ${ }^{2}$, and aside from the fact that additional LE spectrum below $3 \mathrm{GHz}$ is still highly desirable, the LEFR is not just a step forward, it is a leap onto a new plateau. It recognizes that licensing is an unnecessary burden when congestion is not imminent, and the opening of the high frequency frontier ${ }^{3}$ in the coming decade will further

\footnotetext{
${ }^{1}$ http://www.ofcom.org.uk/consult/condocs/lefr/

${ }^{2}$ However, the Commonwealth Scientific and Industrial Research Organisation (CSIRO) is developing an integrated circuit for transmissions in the $180-220 \mathrm{GHz}$ band which relays data at $80 \mathrm{~GB} / \mathrm{s}$. They say the chip is "more cost and power efficient than current wireless chips [and] can be used in both indoor and outdoor wireless networking." See "CSIRO speeds wireless chip to 80 gigabits per second," by Mitchell Bingemann, ComputerWorld, 13 April 2007 - http://www.computerworld.com.au/index.php/id; 1568566448;fp;16;fpid;1. A few months ago, engineers at the University of California at Los Angeles achieved the highest frequency ever generated with a CMOS "chip" - $324 \mathrm{GHz}$ - and asserted that minor changes in the design would enable operation up to $600 \mathrm{GHz}$. The use of CMOS proves these circuits can be mass-produced with current manufacturing techniques. See "Engineers Set New World Record In Generation Of High-Frequency Submillimeter Waves”, Space Daily, 17 April 2007 http://www.spacedaily.com/reports/Engineers_Set_New_World_Record_In_Generation_Of_High_Fre quency_Submillimeter_Waves_999.html. These reports (and others) suggest that the high frequency "frontier" will open in the next decade, activating much more spectrum than is used today.

${ }^{3}$ Research in the terahertz region (over $1000 \mathrm{GHz}$ ) is also making rapid progress even though "the fundamental hardware to build a commercial wireless THz communication system does not exist today..." (Terahertz Technologies, $R \& D$, Commercial Implication and Market Forecast, a report by Fuji Keizai USA, 12 June 2007 - http://www.reportlinker.com/p050586/terahertz-technologies.html). Currently, only frequencies below $3000 \mathrm{GHz}$ fit the definition of "radiocommunication" in No. 1005 of the Annex to the ITU Radio Convention. But the Chairman's report to WRC-07 is expected to include a discussion of regulatory projects above $3000 \mathrm{GHz}$. ("Question ITU-R 228/1: Possibility and relevance of including in the Radio Regulations frequency bands above 3000 GHz,” August 2003 - http://www.itu.int/dms_pub/itur/opb/que/R-QUE-SG01.228-2002-MSW-E.doc.
} 
weaken the belief that spectrum is scarce, at least for short-range communication. When I first read the LEFR consultation document, I must confess that I was speechless with excitement. In 2005 the Spectrum Framework Review (SFR) final document had said,

\begin{abstract}
"As a maximum, then, an additional $250 \mathrm{MHz}$ or so of spectrum might be needed for licenceexempt use... Additional spectrum available for licence-exempt use will prevent licensed use with resulting loss in value...

"Spectrum above $30 \mathrm{GHz}$. Our assessment was that there was no need for a large increase in the supply of licence-exempt spectrum. This was supported by almost all respondents. We do not, therefore, agree that this spectrum should be licence-exempt". ${ }^{4}$
\end{abstract}

What changed between the SFR and the LEFR? Did Ofcom discover new applications needing huge amounts of spectrum which would be worth more if unlicenced? No, they got a consultant's report which said more spectrum was available between 30 and $1000 \mathrm{GHz}$ than could be filled by applications likely to develop in the next 20 years and there are no physical obstacles to the production of affordable equipment to exploit that spectrum. ${ }^{5}$ What changed, in other words, was the perception of supply rather than the expected demand. That lifted the burden of estimating the value of possible licence exempt uses in order to justify an increased allocation.

There are still inconsistencies in Ofcom's treatment of licence exemption, due to habits of thought and assumptions so entrenched that they remain almost unnoticed. Unless these are weeded out, someone may stand here in 2 years and tell you that policy has shifted again and Ofcom is going to require licences for red light-bulbs while green light-bulbs remain exempt and yellow will be the subject of intensive and sophisticated study by highly paid consultants.

So today I want to focus on the need for more and better thinking about spectrum in general and Ofcom's role in the wireless ecosystem, not on the need for more licence exempt bands. Quantity now is not as important as quality. British punk rocker Billy Idol described our present situation with amazing prescience when he said, "Too much is not enough".

Let's start with the LEFR consultation document. That document admits that deciding which spectrum should be licenced and which should be exempt still needs more thought:

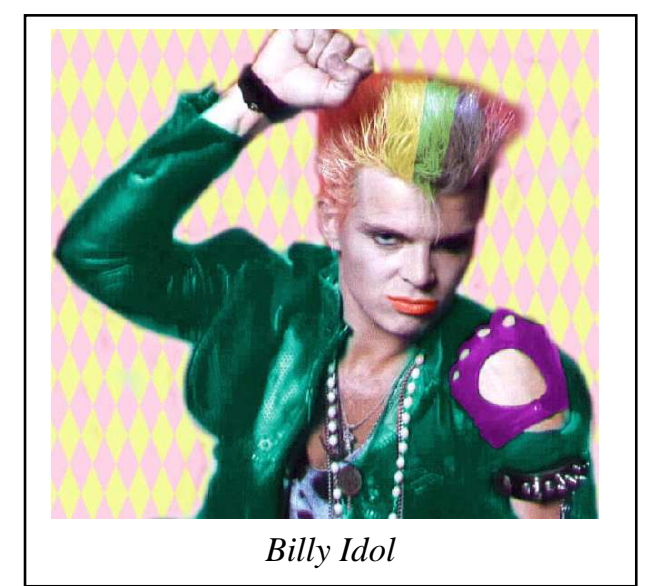

"If it were possible, we would ideally like to allocate spectrum for licence-exempt use through a market mechanism.

"To date, the view has been that market mechanisms are unlikely to be able to allocate spectrum for licence-exempt uses because it is difficult for multiple licence-exempt users to join together to purchase spectrum at auction... [so] despite the desire to make use of market mechanisms, regulators will need to decide on the appropriate location and amount of spectrum for licenceexempt use."6

\footnotetext{
${ }^{4}$ SFR final document, pages 28, 54 and 85 - http://www.ofcom.org.uk/consult/condocs/sfr/sfr/sfr_statement

${ }^{5}$ Higher frequency bands for licence exempt applications - Final report to Ofcom, Quotient Associates Ltd., Indepen Consulting Ltd. and the University of York, February 2007 - http://www.ofcom.org.uk/ research/technology/overview/ese/higher/final.pdf. Path loss is so high at these frequencies that practically attainable ranges are limited to a few kilometres with line-of-sight propagation, and much less in bands with especially high absorption from molecular resonances.

${ }^{6}$ LEFR consultation document, page 12.
} 
The consultancies looking at "collective use of spectrum" for the European Commission last year also concluded that "most decisions on whether to designate spectrum for collective use will need to be made administratively". ${ }^{7}$ But they noted that this is not a good solution, mainly because regulatory decision-making is neither transparent nor objective and harmonising the results of the decisions takes too long. ${ }^{8}$ Professor Cave called the administrative approach "arbitrary and unsatisfactory". 9 The huge shift from the SFR (2005) to the LEFR (2007) in bandwidth proposed for licence exempt use - with no significant change in the predicted applications - shows the arbitrariness. $^{10}$

So must we accept an "arbitrary and unsatisfactory" method as the best one possible? I can think of at least two other ways to look at the problem which might lead to new solutions.

Consider the railroad. On long-distance train trips, passengers may choose whether to travel First or Second Class, paying different prices according to their chosen class. On the continent, one can often choose to sit in a cabin or in a wagon with open seating, and the price paid for the ticket corresponds to the degree of isolation from other passengers. Would train travel be attractive if the managers of the railroad chose who gets First Class seats and who gets Second Class? Or who gets private cabins and who the open wagons?

The tradition in radio is that regulators decide whether users get exclusive or shared spectrum, and this decision is made before channels are assigned. Once made, it is difficult for the regulator to change the decision, and virtually impossible for the spectrum user to change it. I would suggest that we ought to move towards letting users decide whether they need shared or exclusive spectrum, or the protection of licencing or the freedom of licence-exemption.

Some countries - like Brazil and Chile - authorise Wi-Fi under both licenced and licence-exempt regimes in the same band, with licenceholders allowed greater power and more protection from interference. In many other countries, radio LANs can operate at $5 \mathrm{GHz}$ in either licenced or licence-exempt sub-bands, and the EC is considering both licenced and unlicenced bands for WAPECS. ${ }^{11}$

Letting users choose the rights regime seems like the way to go, even when the regulator still decides how much bandwidth to make available. Shifting the choice of regime to the user eliminates the "command" part of "command \& control", which is a significant improvement, since that is the offensive aspect of the approach.

\footnotetext{
${ }^{7}$ Study on Legal, Economic \& Technical Aspects of 'Collective Use of Spectrum' in the European Community - Final Report, by Mott MacDonald Ltd., Aegis Systems Ltd., IDATE, Indepen Ltd. and Wik Consult (November 2006), page 13 - http://ec.europa.eu/information_society/policy/radio_spectrum/docs/ workshop_collective_use/cus_rep_fin.pdf

${ }^{8}$ ibid., page 117.

9 "New spectrum-using technologies and the future of spectrum management: a European policy perspective", by Martin Cave, in Communications: The Next Decade, edited by Ed Richards, Robin Foster and Tom Kiedrowski, Ofcom (November 2006), page 224 - http://www.ofcom.org.uk/research/ commsdecade/

${ }^{10}$ More precisely, the shift shows the effect of removing the burden of estimating the value of potential applications when deciding how much spectrum to allocate for licence exempt use. The European Commission's Authorisation Directive (2002) suggests that burden should be on licenced use.

${ }^{11}$ WAPECS is an acronym used as a term of art for technology- and service-neutral radio spectrum allocations. See "Opinion on Wireless Access Platforms for Electronic Communication Services," Radio Spectrum Policy Group, RSPG05-102final (23 November 2005) - http://rspg.groups.eu.int/doc/documents/ meeting/rspg8/rspg_05_102.pdf.
} 
Giving users this sort of flexibility may be less spectrally efficient. But flexibility can be worth more than efficiency when scarcity is no longer the over-riding issue. Flexibility can also be considered a different kind of efficiency (see box at right).

Another way to look at the problem is through the eroding distinction between licenced and licence exempt uses. Ofcom has access to the regulatory space between licenced and exempt, and has started creating new authorisation classes in that space:

- "Light" licencing

- "Recognised Spectrum Access"

- "Self-coordinated links"

\section{There are different kinds of efficiency}

Functional efficiency: The extent to which the use of radio spectrum meets a user's specific needs, enabling a task to be carried out more effectively.

Economic Efficiency: Creating the most value with the least (or least costly) inputs.

Spectral Efficiency: Using the least amount of spectrum to transmit the greatest amount of information.

Flexibility supports functional efficiency even at the cost of economic or spectral efficiency.

These intermediary classes constitute another liberalisation pathway, so one can expect further blurring and complication of the licenced/exemption boundary. The SFR noted that one may draw "a hard distinction" between "command \& control" and "market forces" but these are actually "two extremes of a continuous scale". The same can be said of licenced and licence exempt $t^{12}$ - which suggests that it may be necessary to think more about how this will affect the market for spectrum rights. Meanwhile, filling the gap between licenced and exempt will make the administrative allocation of spectrum to these different categories less important - as will movement toward service-neutral bands.

I can't fully resolve these problems in my 15 minutes of fame up here today. All I am trying to do is show that new factors can be brought in to dispel the notion that we must accept an unsatisfactory solution as final. The lack of an auction-based approach does not mean there are no other ways to harness market dynamics for allocation decisions. It just needs more thought.

So the first topic I propose as needing more thought is:

How to move away from "command-and-control" in deciding when to licence and when to exempt?

Second:

What are the consequences of eroding the distinction between licenced and licenceexempt, with regard to auctions \& trading, the market price of spectrum and allocating by "command \& control"?

And third:

What principles should guide spectrum management when the high frequencies come into wide use, and scarcity (and thus efficiency) are no longer over-riding concerns?

\footnotetext{
${ }^{12}$ See "Beyond Licenced VS. Unlicenced: Spectrum Access Rights Continua" by Robert Horvitz, ITU

Workshop on "Economic Mechanisms for Spectrum Management," Geneva, Switzerland, 23 January 2007

- http://www.itu.int/osg/spu/stn/spectrum/workshop_proceedings/Background_Papers_Final/ITU-Horvitz-

FINAL.pdf
} 
In the short-term we can and must continue distinguishing between licenced and licence exempt because their rules are so different. Even though the definitional boundary is getting complicated, it is still not flexible and the market cannot yet alter it. In addition, increasing the amount of spectrum for licence exempt use exacerbates the problem of the regulator not knowing how many users there are. So there is a growing need for regular monitoring of the level of activity in the LE bands, to determine if and when more spectrum

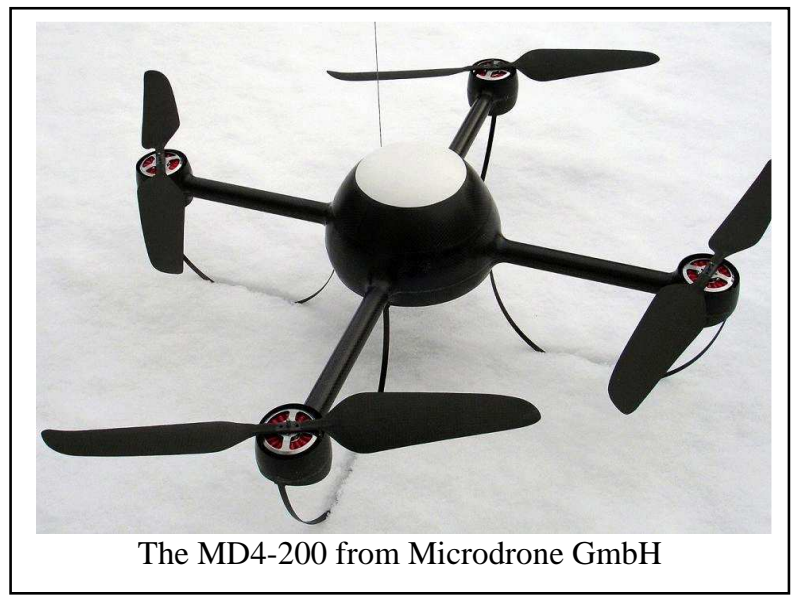
is needed to alleviate congestion. So my $4^{\text {th }}$ needs-more-thought topic is:

How to monitor licence exempt bands for early warnings about congestion? Before eschewing "command \& control" for some better approach, how can the regulator determine the amount of LE spectrum needed to avoid congestion?

Given the short range of most licence exempt devices and uncertainty about where they operate, field-monitoring is bound to be a challenge. A good solution might be aerial surveys performed with a low-and-slow-flying remotely controlled helicopter like the MicroDrone MD4-200 (the Manchester police use this model for surveillance). ${ }^{13}$ Ofcom may be able to borrow one for a test flight. The survey made with Capital Radio's "traffic spotter" airplane in 2002 (reported in "The State of Wireless London" by Julian Priest ${ }^{14}$ ) shows how efficient this technique can be.

\section{Is the $2.4 \mathrm{GHz}$ band congested?}

- Aegis/Transfinite calculated that $\mathbf{2 4 . 7 9} \mathrm{Wi}-\mathrm{Fi}$ access points in $1 \mathrm{~km}^{2}$ is "full occupancy" if no other device types operate in the same band. As few as $\mathbf{4}$ access points per $\mathrm{km}^{2}$ could constitute "full occupancy" if realistic densities of microwave ovens and Bluetooth devices are included.

- Municipal Wi-Fi "hot-zones" typically have $\mathbf{1 0}-\mathbf{2 0}$ nodes $/ \mathrm{km}^{2}$ - more if meshed.

- A "haphazard" survey by Peter Cochrane in January 2007 found $\sim \mathbf{2 0 0}$ nodes $/ \mathrm{km}^{2}$ in the blocks around London's Liverpool St. Station.

- RSA's 2007 Wireless Security Survey found 7130 public access and office Wi-Fi nets in 1300 hectares of east/central London, or about 530 per $\mathrm{km}^{2}$ - not including residential nets.

- Ofcom's 2006 survey of the $2.4 \mathrm{GHz}$ band found it "under-utilised" even in London. Is that good news - or evidence of an inadequate monitoring protocol?

Notes: Evaluating Spectrum Percentage Occupancy in Licence-Exempt Allocations - Final Report by Paul Hansell, Selçuk Kirtay, Iain Inglis, John Pahl and Steve Munday, Aegis Spectrum Engineering and Transfinite Systems Ltd., 7 July 2004 - http://www.ofcom.org.uk/research/ industry_market_research/technology_research/ ses/ses2003-04/ay4529/perc_ocp_lisc.pdf. "Peter Cochrane's Blog: Wi-fi London”, Silicon.com http://networks.silicon.com/mobile/0,39024665, 39165548,00.htm. "The Wireless Security Survey of London, $6^{\text {th }}$ edition”, RSA, June 2007 - http://www.rsa.com/solutions/wireless/survey/wireless_security_survey_london_ 2007.pdf. Data about the geographic size of the districts surveyed comes from the Office for National Statistics.

\footnotetext{
${ }^{13}$ For other alternatives, see Flight International's online directory of unmanned airborne vehicles (UAV) currently on offer from commercial firms - http://www.flightglobal.com/Directory/Search.aspx? navigationId=372\&aircraftCategory $=\mathrm{UAV} \&$ manufacturerType $=\mathrm{UAV}$
} 
Clearly what is needed is some combination of field-monitoring of signals, fact-collection from equipment vendors and importers (market surveillance), and procedures for gathering interference complaints from the public (even if Ofcom has no obligation to resolve those complaints.) This is particularly urgent for the $2.4 \mathrm{GHz}$ band, which has given London the title of "hotspot capital of the world", although other LE bands need to be monitored, too.

It is more than a bit surprising that Ofcom's most recent Communications Market Report ${ }^{15}$ totally ignores licence exempt devices, even though UK citizens probably spent about 2 billion euros on them last year ${ }^{16}$ If Ofcom produced a Communications Market Special Report on LE devices, then added a chapter about them to the annual Communications Market Report, this would generate interest in and justify a more ambitious monitoring programme for the LE market and fill a hole in the available market data.

\section{Ofcom's current work plan includes} topics which need more thought:

- "a vision for our future role in relation to spectrum markets"

- "the scope for a new approach to spectrum usage rights."

- "how to make available the UHF spectrum released by digital TV switchover"

- "prospects for local TV"

The title of today's event suggests that some of those involved in spectrum reform in the UK have thought so long and so hard about the issues that they wonder if their understanding of radio use management is now perfect and complete.

Are they really that cocky? The title of William Webb's presentation today suggests they are, but Ofcom's "Programme of Work for $2007 / 8^{\prime 17}$ indicates otherwise. There we see that Graham Louth is in charge of developing "a vision for our future role in relation to spectrum markets" while Professor Webb explores "the scope for a new approach to spectrum usage rights". Meanwhile, Matthew Conway directs the Digital Dividend Review (DDR), which is proving to be Ofcom's most controversial piece of unfinished business. Ofcom may think it has already found the right approach to the Digital Dividend - a service-neutral auction is a direct manifestation of their spectrum reform strategy. However, the responses to the DDR consultation show many people disagree.

These responses also suggest that Ofcom needs to think more about how to convince a skeptical public that its "economistic" approach to spectrum reform is correct. It is important to recognise that the new orthodoxy which treats spectrum as just another resource, a tradable commodity, rather than a "priceless" privilege that comes with unique moral, political and cultural responsibilities (as it was when radio was synonymous with broadcasting) - this new "let the market decide" ideology - took hold quickly, after generations of consensus on the opposite viewpoint. Insiders familiar with the reasons for the new attitude may consider the change rather too long in coming. But for the broad public it has been fast enough to cause disorientation. After all, for the better part of a century it was characteristically British to ridicule a "merely" economic view of radio as vulgar and unprincipled - as too American.

\footnotetext{
${ }^{14}$ http://informal.org.uk/people/julian/publications/the_state_of_wireless_london/.

${ }^{15} \mathrm{http} / / /$ www.ofcom.org.uk/research/cm/cm06/cmr06_print/

16 "Probably" is the best we can say as there is an urgent need for more accurate data. The figure of 2 billion euros is a back-of-envelope calculation based on the "Estimated size of the collective spectrum use market" in the European Union for 2006, given in Figure 2 (page 7) of Study on Legal, Economic \& Technical Aspects of 'Collective Use' of Spectrum in the European Community (see note 7 for URL). The UK's share of the market was calculated by multiplying the EU total - 14 billion euros - by 0.142931 , which is the ratio of the UK's GDP to the EU's GDP in 2006, according to Eurostat.

${ }^{17} \mathrm{http} / /$ www.ofcom.org.uk/about/accoun/reports_plans/annual_plan0708/projects/
} 
"To the right kind of man, a dividend motive is unnecessary. More than this, the serving of public interest and the serving of financial interest are not normally fully compatible."

\title{
---Sir John Reith, 1932 (BBC Director General) ${ }^{18}$
}

\begin{abstract}
"The wavebands available in any country must be regarded as a valuable form of public property; and the right to use them for any purpose should be given after full and careful consideration... Under any system of competitive broadcasting all these things would be at the mercy of Gresham's Law. The good, in the long run, will inevitably be driven out by the bad."
\end{abstract}

---The Sykes Broadcasting Committee, $1923^{19}$

What is needed is patient dialogue with those who believe the Invisible Hand of the market has dirty fingers. So my $5^{\text {th }}$ needs-more-thought is:

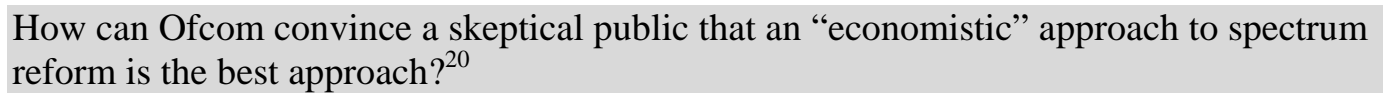

And I would extend the need for more dialogue to Ofcom's relationship with wireless communicators and service providers - the regulatees. Relying on the market to make decisions that had been reserved for regulators means transforming a rigid and restrictive but predictable top-down framework for private radio use into a dynamic bottom-up arena encouraging competition, flexibility, innovation and risk-taking - in other words, an ecosystem. The intent may be to rely more on self-regulation, but tweaking and refereeing will still be needed, for the transition at least. That means further major changes in the way Ofcom operates, from a managerial to a collaborative mode.

Right now, for example, consultations are launched by senior staff based on refined strategies and an integrated workplan. Topics for consultation are never suggested by service providers or the general public through the submission of complaints or one-off requests for rule changes, as is common in the US. Ofcom also has a small number of close advisory committees - clubs, really - whose meetings are private and whose members are selected in formal, legally mandated processes.

I would suggest that to create an ecosystem which is successfully self-regulating, there will need to be a larger number of small informal citizen-staffed bodies working with Ofcom, whose meetings are open to anyone. The meeting with DDR stakeholders from the licence exempt community last Wednesday was a step in the right direction, as it involved genuine multilateral conversation, not "we talk, you listen." But I understand that this was the first meeting of its kind. So add this to the list of things needing more thought:

How can Ofcom increase its interaction with the wireless ecosystem it wants to develop? How can it evolve from directing events to collaborating with many others as a facilitator $?^{21}$

\footnotetext{
${ }^{18}$ Quoted in History of Broadcasting in the United Kingdom: 1927-1939 by Asa Briggs (Oxford University Press, 1995), page 383.

${ }^{19}$ Quoted in "Public service broadcasting: the history of a concept" by Paddy Scannell, in volume IV of Television: Critical Concepts in Media and Cultural Studies edited by Toby Miller (Routledge/Taylor \& Francis Group, 2003), pages 212-227.

${ }^{20}$ According to William Lehr, "The allocation of additional dedicated unlicensed spectrum will help defuse opposition to flexible licensing and may be more likely to gain support than an attempt to pass secondary use easements..." See "Economic Case for Dedicated Unlicensed Spectrum Below 3GHz" (2004) http://itc.mit.edu/itel/docs/2004/wlehr_unlicensed_doc.pdf

${ }^{21}$ Two thoughtful perspectives on these issues are "Adaptive Regulation: Contours of a Policy Model for the Internet Economy" by Barbara A. Cherry and Johannes M. Bauer, presented at the International Telecommunications Society meeting in Berlin, 2004 - http://userpage.fu-berlin.de/ jmueller/its/conf/
} 
Finally, the word "liberalisation" has acquired a very specific meaning in spectrum policy, narrower than its meaning in other contexts. In spectrum it means replacing "command \& control" with market forces. This is an "economistic" view of liberalisation.

However, any student of comparative law knows that the authoritarian legal tradition is based on the assumption that everything is forbidden which is not specifically authorised. The opposite of that is the liberal tradition, which says anything not specifically forbidden is permitted.

Radio regulation is still - by and large - a manifestation of authoritarian thinking. If you remember nothing else of what I said today, I would be content to have you remember this: spectrum reform should aim for liberalisation as lawyers understand it, not just the economists' version:

How can spectrum policy move toward the position that anything not specifically forbidden is allowed, rather than staying within the authoritarian tradition which assumes everything is forbidden unless explicitly authorised? $?^{22}$

I believe people are attracted to and excited by the licence exempt bands because these embody the hope of finally leaving radio's authoritarian past behind. It's more than a practical preference, but less than a yearning for anarchy.

The LEFR shows how a liberalised regime - liberalised in the legal sense - could be organised on a far grander scale than has ever been attempted before. That's what makes it so important.

berlin04/Papers/Cherry_paper.pdf and "From Consumers to Users: Shifting the Deeper Structures of Regulation Toward Sustainable Commons and User Access," by Yochai Benkler, Federal Communications Law Review, Volume 52, Number 3, pages 561-580 (April 2000) -http://www.law.indiana.edu/fclj/pubs/ v52/no3/benkler1.pdf

${ }^{22}$ This question was inspired by the new licencing policy adopted in 2004 by Brunei's Authority for the ICT Industry (AiTi). The new policy is based on "a more generic description of the classes of [permitted] activities, complimented by a negative list approach to allow AiTi to prohibit specific types of services or method of implementation." See "Information on APT Broadband \& ICT Brunei Darussalam," presented at a meeting of APT's Telecommunications Development Forum in Bangkok, Thailand (28-29 June 2004) - http://www.aptsec.org/meetings/2004/ADF/ADF-INPUT/ICT\%20Profile/Brunei\%20APT \%20Broad band $\% 5 B 1 \% 5 \mathrm{D}$.pdf. 